\title{
Mobile Learning for Special Preschool Education
}

\author{
http://dx.doi.org/10.3991/ijim.v10i1.5288 \\ Georgia K. Kokkalia and Athanasios S. Drigas \\ NCSR DEMOKRITOS, Institute of Informatics and Telecommunications, Net Media Lab, Athens, Greece
}

\begin{abstract}
Nowadays the development of the Mobile Learning (ML) in children's progress is thought significant. However, its role in special preschool education is recognized crucial, as it is a tool that can foster the knowledge and the experiences for this sensitive age. The support of specific areas in preschool education according to the educational perspective is thought significant with the maintenance of the mobile applications. In this paper we present a brief overview of the most representative studies of the last decade (2005-2015), which concentrates on skills that are examined in special kindergarten (early literacy, early mathematics, cognitive, social-emotional) and are supported by the mobile learning. The effectiveness of mobile applications in children who are autistic and face attention deficit problems is examined. The role of mobile learning in preschool children who face mental problems is also investigated.
\end{abstract}

Index Terms-preschool education, mobile learning, special education

\section{INTRODUCTION}

Historically, new technology has been seen as a potential solution to increase educational attainment because it provides the trial to transform the education environment in the real classroom [1]. As a result, technology has been noted to promote learning practices especially in the sensitive area of the preschool education scoping to build collaborative learning environments with the assistance of authentic challenging, multidisciplinary and developmentally appropriate new technologies [2]. Additionally, child -centered practices focus on motivating and engaging learning activities that are related to children's real lives and thus, technology, and tablets more specifically (mobile learning) can alter classroom practices and have implications for teaching and learning [3].

Many researchers support the view that the development of multimedia application for children's education has become very popular today. There are many advantages offered by the mobile learning especially in the field of the educational area (development of fundamental arithmetic and literature skills, improvement of basic cognitive and emotional skills, support of collaboration etc.) and in the area of the preschool special education [4]. As many studies suggest, the use of the mobile applications and the learning activities that are offered by them may increase children's interest during the learning process due to its success in attracting children's attention with the multimedia elements existed in the application. In addition, there are a lot of studies that showed that by including the appropriate and suitable learning theories into multimedia application children will be able to learn more effectively [5].

Furthermore, preschool children are exposed to handheld/ mobile technology or devices like smartphones and tablets and their interaction with these devices are increasing since the devices are easy and not expensive. Children are starting to use touch screen devices very young and they have become comfortable with touch screen technology, although they do not have their own smartphone or tablet but they can use their parents' smartphone or tablet. Most touch screen devices are easy for children to handle [6] and thus mobile technologies are highly motivating and more engaging than traditional classroom tools [7]. Tablet computers, specifically, can be used anywhere /anytime and foster individualized learning, such that teachers can use the devices as tools for scaffolding learning [8]. Additionally, tablets offer a unique home-school connection by providing children with a classroom experience that relates to the technology real world. Also, using mobile device as a learning tool is a new way for children to learn anywhere and anytime they like. Moreover, an application that contains multimedia elements such as animation, graphic and video encourages parents to attract the attention of their children with it. In the light of the above references, there are many studies that showed that there are improvements in terms of children performance before and after they used the multimedia mobile application as a learning tool in the areas of language information, learning skills, cognitive strategy, attitude, emotion, and motor skills (Ni \& Yu, 2015).

On the other hand, many researchers support the view that children with special educational needs face difficulties to develop cognitive abilities and acquire new knowledge. According to many studies, these children have to improve their behavior, communication and relationships with their environment in order to improve their learning and daily life. The development of appropriate and adaptable applications provides them with many benefits as it helps to improve the learning process to different cognitive, sensorial and motor domain [10]. The increasing number of children who need special education also requires an increasing amount of resources from teachers and a restructuring of the education system. Mobile learning can be a part of the solution to this resource problem, however, for the technological solution to work, technologies need to be designed and implemented in new ways [11]. Mobile applications used in special education try to help children with special needs to communicate and struggle about even with the most basic of concepts.

In this paper, we try to present some of the most important and serious mobile intervention applications that assess preschool children with special educational needs. A brief overview of the most representative studies of the last decade (2005-2015) is presented according to the educational perspective. Specifically, applications that support children who face difficulties in the area of the literature and math are presented while tools that help children with autism and attention deficit hyperactivity disorder (ADHD) are explored. Finally, applications that 
support children who face mental and physical disorders are investigated.

\section{Mobile LeARNING For CHILDREN WHo FACE LITERACY DIFFICULTIES}

There are an increasing number of children who need special education and require an amount of resources from teachers and a restructuring of the education system. New technology can be a part of the solution to this resource problem if technologies are designed and implemented in new ways. Technologies used in preschool special education can roughly be divided into four basic categories that include assistive and communication technologies, learning software and the newest category of educational robotics, which have successfully been used in the educational area of the kindergarten. From this point of view, children with individual educational needs as well as those involved in inclusive education could benefit from the use of technology [12].

In the light of the above view, Mobile Learning (ML) has increasingly attracted the interest of educators, researchers, and companies that develop educational systems and publish learning materials. This kind of technology provides the potential for collaborative interaction and learning opportunities for all people [13]. Mobile Learning is potentially useful in more educational settings as do not require technological training, do not intimidate users, and remain unobtrusive in classrooms [14]. In addition to constituting a new technology, mobile learning implies a new methodology that asks plenty of things, from the design of new didactic resources adjusted to the terminals and mobility, to the pedagogical principles that exist behind them [15].

Taking the above into account, Fernadez- Lopez et al. [16] developed a platform called Picca, for children with educational special needs. The designers made a mobile platform based on iPad and iPod touch devices, in order to cover the main ideas of the learning process, which are the preparation, use and the evaluation. This platform includes four kinds of educational activities, which can be used by teachers depending on children needs. The results of their experiment shows that the use of the Picca is associated with positive effects in the development of learning skills for children who have special educational needs, claiming that the basic skills have been improved. Besides, in many cases children have the opportunity to perform activities that previously were not accessible to them, as the interface and the contents of the activities have been designed in order to be appropriate to them. The study also suggests that the type of activities provided is developmentally appropriate for learning purposes as well as the use of electronic devices and multimedia contents increases children's interest in learning and attention.

In addition, children with special needs often struggle to communicate about even the most basic of things. For children who cannot talk and communicate with ease educational communicative tools can enable them to get their needs met, to socialize, and learn [17]. According to another study, Mocotos, a new class of mobile communications tools for children with special needs includes a portable device not much larger than popular cell phones and both children and adults can use the mobile screen on the device for interaction activities. Teachers and specialists may program the devices while the primary interface metaphor consists of virtual cards. The Mocoto comes preinstalled with a comprehensive library of cards and users can also add custom cards to the interface by taking pictures, scanning in materials, or creating other images. Each card includes both a name and other information that is needed, which enable the categorization, searching and management of the cards. The type of the tool is to provide a rich interface for various programming and customization activities. Furthermore, the device itself is then reserved for rapid access to the library of virtual cards and supports pre-planning as well as the daily activities that occur in all classrooms. The program is flexible enough to present multiple functions supported by different devices inside the classroom besides the use of custom audio cues for the cards may support a variety of communication and learning activities from highly structured communication during an educational activity to unstructured impulsive words [18].

Moreover, advances in mobile technology have given rise to tablet devices that have been rapidly bought by consumers and put into the hands of children of all ages. Alphabet books are increasingly produced and are presented to parents as being beneficial to children's emergent literacy skills. This study is directed at providing information about how young children interact with electronic alphabet books as it is believed that storybook reading in kindergarten is important for children's vocabulary development [19]. The new mobile devices can be used to enhance reading to children, but a more intensive training seems necessary to further enhance vocabulary learning [20]. The current research focuses on kindergarten children with special needs as a result of physical disabilities and aims to explore whether vocabulary training can enhance their vocabulary learning and to find out whether their task-on-behaviour differed when story reading was carried out by the teacher or by a mobile device. However, the study shows that children with special needs were equally able to maintain their attention on the story when it was read by the device as when it was read by the teacher. There were no differences in learning results between the experimental and control group between pre-test and post-test, probably because both groups had the story read to them and could thus learn new words. The experimental group had an additional intervention in the form of mobile vocabulary games, which may have compensated for possible higher learning findings from listening to the teacher. Lastly, the group of kindergarten children with special needs seems to enhance their vocabulary by working with an appropriate program without teacher support. Nevertheless the researchers state that because of the small size of the subject group, there is a need for further studies with more children, scoping on the results of the program especially designed for this population [21].

Last but not least there is the general opinion that iPad applications are being used as an additional tool for learning within educational environments improving the academic skills of at-risk preschoolers. A recent pilot study investigated the efficacy of iPad applications in improving the literacy and overall academic skills in at-risk preschoolers. Results suggested that while statistical significance was not obtained, practical significance was found for the use of iPad applications to support learning in the preschool skill areas of alphabet knowledge and number concept. Also, the iPad applications that were chosen for this project were selected with several key criteria in mind and mainly focused on the key academic concepts. Be- 
sides, they were developmentally appropriate for preschool age children with several levels of difficulty through which children could move independently, according to their needs and they provided positive or neutral feedback to children's responses. For the intervention condition, the applications gave multiple opportunities for the child to learn about and practice at least one of the skill areas [22].

\section{Mobile Learning For ChILdRen Who FACE EARLY MATHS DIFFICULTIES}

There has been a growing opinion that preschool education provides a tight basis for later school learning [23]. School-entry mathematical skills may predict later academic achievement even after family background and cognitive and socio-emotional factors have been controlled [24]. A dynamic way to enhance school achievement in mathematics and to prevent learning difficulties is to improve basic academic skills of low-achieving children before they go to school [25]. As Aunola, Leskinen, Lerkkanen, and Nurmi [26] showed from the beginning of preschool to second grade the growth of math competence was fastest among those children who entered kindergarten already equipped with a higher level of mathematical skills and it was slowest among those whose initial level was lower. There is therefore a need to develop more individualized interventions for at risk children to support their early learning in mathematics. However, recent neuropsychological research suggests the existence of core numerical processes that are the foundation for learning basic number skills and arithmetic. Many components of cognitive processing have been connected to poor performance in mathematics and many children with learning difficulties in math show extremely diverse problems with arithmetic, which appear to come from different sources in different children [27] .

In recent years, with the appearance of smart applications and programs several researchers have proposed the use of many devices such as tablets and mobiles [28]. Particularly in the subject of mathematics, Zaranis [29] made a comparison between the learning outcomes of computer based teaching and mathematical teaching, aiming the teaching of "Realistic Mathematics" for kindergarten children. Compared to the traditional teaching method, results showed that mobile learning enhance the development of mathematical skills and the cultivation of a deeper perceptual ability for the pupils.

However, other meaningful approaches, focused on the use of touch-screens by children with some type of cognitive disorder, which may affect their ability in math and literature. The current studies showed that it is possible to obtain significant results, especially in promoting collaboration and motivation, although these studies cannot be used as a reference for normal children's behaviour with touch-screens. Furthermore, many studies support the view that iPad applications are being used as a tool for learning within educational environments. According to a conducted research, which investigated the efficacy of iPad applications in improving general academic skills in at-risk preschoolers, its findings indicated that practical significance was found for the use of iPad applications to support learning in the preschool skill areas of alphabet knowledge and number concept [30].

Furthermore, another research team investigated the effectiveness of two different programs on kindergarten children with low numeracy skills on number skills [31]. Children with low numeracy skill were randomly allocated to two treatment groups. While the first group played a computer game (The Number Race) which emphasized numerical comparison and was designed to train number sense the other played a game (Graphogame-Math) which emphasized small sets of exact numerosities by training matching of verbal labels to visual patterns and number symbols. Both groups participated in a daily intervention session for three weeks and children's behavior in different mathematical tasks such as counting and number comparison, were measured before and after the intervention. As a result, both interventions seemed to improve children's skills in number comparison, compared to a group of typically performing children but not in other areas of number skills. These findings, together with a review of earlier intervention studies, provide guidance for future work on educational mobile tools aiming to boost numeracy development of low performing children [31].

Moreover, a research group demonstrated the design of a Joyful Classroom Learning System (JCLS) with flexible, mobile and joyful features [32]. The theoretical background of this research includes the experiential learning theory, constructivist learning theory and joyful learning. The developed JCLS consist of the robot-learning companion sensing input device, mobile computation unit, mobile display device, and wireless local network with the support of an operating software. The developed JCLS system has been applied in real world for supporting children to learn mathematical multiplication. As a result, both pilot experiment and formal experiment were conducted and the findings showed that the JCLS can provide kindergarten children who face learning difficulties with more opportunities for hands-on exercises and deepening their impressions about the learning contents. Having many opportunities for hands-on exercises children can have more thinking time for knowledge construction and can increase learners' motivations and offer a more joyful perception to learners during the learning process. On the other hand, the JCLS can support teachers to immediately acquire the learning attitude of every child for applying the most suitable and appropriate instructional strategy and giving after-school assistances [32]. In addition, the results of the study show that the JCLS can help children to have better learning experiences in terms of experiential learning, constructivist learning and joyful learning as many of them seem to increase their learning motivations and help them concentrate on the instruction and learning activity especially in the field on math.

Additionally, in the area of mathematics education it is believed that Web Apps for the iPod Touch provide many ways for students to exercise and investigate mathematical problems [33]. Firstly, Flash Math is a basic drill program that presents the child with a set of timed problems. Settings for addition, subtraction, multiplication, and division, as well as choices for the number of place values to include in problems the number of problems to present, the time for each problem and progressive time adjustments makes this application friendly for the student. As a result, teachers could certainly use this application to provide each child with the types of arithmetic practice that they need in order to become more proficient in their mathematics classroom. In addition, Math Quiz expands this type of work to include squares and square roots and includes controls for presenting problems in random or 
sequential order. The problems are answer via a type spin wheel with audio clicks, which could be entertaining for the students using the app. Math Quiz continues to provide problems to the user for the duration of the experience nevertheless the lack of a stopping point could be a frustration for some students, but others could find that they enjoy the continual challenge [33].

Last but not least, Tomi and Rambli [34] in their research present the development of an interactive mobile augmented reality magical playbook for kindergarten children in learning numbers using an old folklore literature, The Thirsty Crow, with the support of a mobile augmented reality application and interactive physical book interface design. According to the authors, Augmented Reality (AR) refers to a technology that offers the ability to the user the sense of the real world while interacting with the virtual and physical object. Additionally, mobile AR application has gaining popularity nowadays due to mobile technology advancement. Mobile refers to portability usefulness of the application itself, thus mobile AR application can be referred as a portable AR application. By applying this concept to the storybook, the physical book will be enhanced by augmenting the virtual object (3D models, animations, and sounds) viewed over a mobile device. This study specifically highlights an innovative development of the interfaces for providing an AR storybook that enhances story reading and learning experience for preschool children via mobile AR application and highly interactive physical book interface design of the AR book. The findings of the study suggest that AR concept of the book successfully grabs children's attention while this application with the book is easy to use especially for young children. Furthermore, the children would likely to interact with the $3 \mathrm{D}$ character on the book besides their excitement of interacting with the book's character using their finger on their reaction. Finally, in math section, students were excited to count together with the $3 \mathrm{D}$ character while interacting with the book. Thus, it shows the users were fully engaged with learning process in a joyful learning environment [34].

\section{Mobile LEARNING For CHILDREN With AdHD AND AD}

Attention Deficit Hyperactivity Disorder (ADHD) is a diagnosis that identifies children who exhibit inappropriate levels of inattention and/or hyperactivity [35] and is associated with poor scholastic outcomes or other learning disabilities [36]. Attention difficulties are one of the most prevalent problems that become apparent during a child's school-life and are usually characterized by poor attention skills and/or hyperactive and impulsive behaviors. These problems usually appear in early age and more specifically are present before the age of seven where often a diagnosis is taken place. A common characteristic of children with attention problems is that they aren't paying attention and they cannot focus on a specific time for an acceptable period. This elevated risk for poor academic achievement indicates that many children who have attention disorders need an accurate diagnosis and effective intervention program as ADHD usually continues into adulthood [37]. Research suggests that successfully management and behavior modification of this disorder often depends on the integrated program of medical interventions and behavioral techniques. A very crucial factor for this scope is to involve parents and teachers in these interventions [38].
Children with attention deficit hyperactivity disorder experience effusive interpersonal difficulties and peer disapproval that go beyond the diagnostic criteria and usually occurs in approximately $3-5 \%$ of the school-aged children. Although minimal research has been done on the effectiveness of technology for children with ADHD, technology is seen as one potential tool that offers promising outcomes for such children. Technology enables the teacher to plan learning activities for children with short attention spans, allowing them to be actively involved in learning, and in turn even increase the child's motivation and confidence [39].

As, a result in order to assist children with memory and attention problems a tool called Cogmed was created [40]. This program has been developed in order to assist children's performance and is available as clinical practice for treatment of ADHD. Their developers claim that Cogmed training improves attention, concentration, focus, impulse control, social skills, and complex-reasoning skills and lastly improves working memory capacity. There are three types of Cogmed training, which are one for preschoolers and older children and include several visuo-spatial and verbal memory tasks. These programs have been embedded in videogames, each of which is performed for roughly 40 min a day, 5 days a week, for 5 weeks. Cogmed JM and Cogmed RM are respectively designed for preschoolers and older children. Specifically, an example of a visuo-spatial task that is included in Cogmed training is "Asteroids" which presents a field of several free-floating asteroids, a subset of which lights up, one-at-a-time and the child must reproduce the sequence via mouse click. Additionally, an example of a verbal task is "Input Module" in which a sequence of auditory digits is played and the child has to reproduce the sequence in reverse using a number-pad that is exposed on a robot's arm. However, although initial studies indicate that Cogmed is a successful intervention tool, there are some concerns about its validity and more research is need to be done. There are studies that state that Cogmed is an unsubstantiated tool and so the future research should place greater emphasis on developing theoretically motivated accounts of working memory training [40].

Moreover, another study compared the advantages of mobile phones as a management device for caring with lecture that is thought the main method for parent's education in this topic. In this survey 60 mothers who have a child with ADHD were selected and divided in two groups. After the pre-test that was based on knowledge and practice about ADHD and its management, one of the groups received educational support from mobile phone and for the other group, lecture was held on. After a period of 16 weeks, the investigators measured again knowledge and level of applying of the trained techniques and the findings of the survey stated that although both training methods had a positive effect on knowledge and management techniques for mothers, the use of mobile phone as a learning supportive and assessment tool, seemed to be more effective. Specifically, the mothers who joined the mobile learning group were successful to control the ADHD symptoms in their children than the mothers in lecture group [41]. 
PAPER

\section{Mobile Learning For ChILdREN With AUtistic SPECTRUM DISORDER}

In spite of the fact that most information about mobile applications use by children with disabilities may be very popular, however, there is research on the use of mobile tools by children who struggle with developmental disabilities. As a result, recent reviews have covered the use of iPods and iPads in teaching programs for people with developmental disabilities and more specifically, with autistic spectrum disorders [42]. According to a brief review on the evaluation of the use of iPods, iPads and related devices in educational programs for individuals with developmental disabilities it was explored that the results were largely positive, suggesting that such devices are important technological support for children with developmental disorders. The outcomes of these studies also claim that children with developmental disabilities can be taught to use such tools for different purposes, specifically for enhancement of academic, communication, and other basic skills. On the other hand, the authors state that some individuals showed difficulty in learning to operate such devices with sufficient motor control, suggesting that other solutions such as Bluetooth can be arranged [42].

Taking the above under consideration, research on autistic spectrum disorder has noted that three main areas have to be investigated in order to help children who face such difficulties which are the early detection and measurement of progress, supporting devices for affect recognition and social skills improvement. Some studies have proved that the iPad may help autistic children to learn as recent iPad applications target specific skill shortages. Firstly, Proloquo2Go, iComm, and TapToTalk, construct an alternative communication system using symbols and text-to-voices, additionally Grace helps autistic children to build sentences from images while iCommunicate allows storyboarding through pictures and images. Moreover, First-Then-Visual-Schedule, enables daily schedules to be taught, iConverse, translates PECS into a iPad application, AutismExpress helps a autistic child understand emotions and finally stories2learn helps create personalised social stories to teach autistic children about different types of communication and social interaction. Despite the fact that these iPad applications target specific shortcomings, there are not tools that target generic, automated stimulus complexity, and frameworks for delivery and recording in a systematic way [43].

Moreover, according to a currently conducted study, Playpad is software for delivering therapy activities and collecting progress results in autistic children. The first version of the system used a custom multi-touch surface, but recently iPads were used. Usually, Playpad is used solo, but sometimes two users may need to collaborate on simple partner tasks. The mobile Playpad receives lessons and media from the application server, which consists of two components a database populated with multimedia content, and a framework for constructing a stimulus. Autism specialists designed a series of lessons that are based on the child's ability and rate. Each lesson consists of media stimuli, which are downloaded as required by Playpad. Results from training are fed back into the system and may give details about child's progress to parents and teachers. According to the developers this portable platform for pervasive delivery of early intervention therapy using multi-touch interfaces and principled ways to deliver stimuli of increasing complexity and adapt to a child's performance. According to the developers, this system was evaluated by therapists who observed positive results across all children, while parents and therapists as this program provides automated multimedia early intervention in this crucial period, they were helped by teaching basic skills. Finally the designers claim that future work will target extension of the system with new category schemata, in its intended role as a wait-list technology [44].

Another research investigated the impact of physical design of social robots on the perceptions and preferences of children, both typical developing and children with autism. As children represent an extremely valuable source of information regarding the appearance of robots, since the physical features of the robots influence their perception, the researchers designed a new and childfriendly method, namely, a robot categorization game, implemented on a tablet device. This picture game is a nonverbal, implicit measure of perception and therefore, it is a method adapted to the abilities of autistic children and pleasant for typical children, in order to have a single standardized method for both groups. The implications of this research, stress the fact that children should play an active role in the process of designing social robots because this study proposes an innovative categorization game, responds to all children's' interests, cognitive and fine motor control abilities. The results of the study showed that the Robot Matching Game has multiple benefits as it offers a window into implicit perception, it can be applied to preschoolers and children with communication problems such as children with autism, it does not rely on language, it is attractive and intuitive, it is easy, it offers an automatic system of storing and organizing the data, it offers flexibility and speed of delivery. According to the designers, the most important conclusion of this study is the fact that both typical and autistic children think robots mainly as toys. Moreover, a significant percentage of autistic children, especially boys, also perceive robots as machines. Therefore the designers propose as a future study that the Robot Matching Game should be used before and after exposing children to physical robots in order to gather important information about the impact of exposure on attitudes and perception. Furthermore, they believe that exploring children's perceptions of robots has important implications for the use of social robots in therapy. Finally the designers claim that robots has to be included in educational or therapeutic curriculum activities, children's perceptions and preferences should be investigated and should influence the design of these applications scoping to a therapeutic role [45].

\section{Mobile LeARning For ChILdRen Who FACE MENTAL PROBLEMS}

With the development of mobile technology many health applications have been designed to address a wide range of medical issues. Mental health tools constitute a huge range of the market application tools, which are considered important for the development of the art therapy. Taking the above under consideration, researchers believe that this happens for some important reasons [46]. First of all, because art therapists do not have an application designed for their needs [47] the development of mental health applications could lead to potentially useful tools for the health field as many health professionals are 
already beginning to use applications in treatment. Many studies have showed that mobile applications may be used to reduce client stress [48] while many of them provide therapist support, physiological sensors, and mood recorders. Additionally, the use of digital technology in the art therapy field appears to follow a new trend [49] as a growing generation has been raised with the presence of digital art technology. It is obvious that children as young as 3 years are using iPads, and digital technology in the regular part of preschool curriculum [50]. Finally, with current technological innovations, therapists can explore new ways to produce and interact with art media while such exploration is critical to the future of art therapy [50].

Furthermore, there are some studies that are related to the development of art therapy application that support children with emotional and mental problems. Firstly, there is an art therapy mobile application called Computer Art Therapy) [51] that offers tools for the analysis of the picture, Kinetic Family Drawing (KFD), and free drawing [51] Many practitioners with the support of the above applications can help children to explore the meaning of their art expressions while some researchers are trying to search different ways to evaluate various characteristics of artwork for mental illness, cognitive and developmental disorders, and personality traits. Another program is the Engaging Platform for Art Development (ePad), which is a touch- screen application tool for use with mature art therapy clients. This application detects the child's level of engagement during the art making process-enabling specialists for further individualization of the art therapy tools [52].

Moreover, art therapists recently made a list of desirable features for an art therapy application. The Art Therapy Draw!, is an intervention tool which includes two of the most serious characteristics the portfolio option, and the strong security. Five art therapists evaluated the tool through a System Usability Scale, which revealed both positive qualities of the program and areas requiring improvement. Overall, the layout of the application proved easy to navigate and required little knowledge to operate, it offered more security measures than other applications and seemed to be suitable for use with disabled persons or those allergic to conventional art materials. The designers conclude that this study marks a step forward for emerging mobile art therapy [53].

Lastly, a current study [54] presented a mobile application called "Sign my World" which focused to aid deaf children to learn the Australian Sign Language (Auslan). This application, which is presented as a mobile video game, explores three important concepts that are the context awareness, personalization and the principles of a video game in order to support deaf children to be familiar with common nouns and verb signs helping them as well to feel comfortable and convenient. The developers claim that the users found it friendly and easy, they enjoyed interacting with the prototype and seemed to learn the incorporated signs after some period of training.

\section{CONCLUSIONS}

Early childhood development is influenced by characteristics of the child, the family, and the broader social environment. Physical health, cognition, language, and social- emotional development maintain school readiness. As a result, early childhood development programs are considered very important for the well being of young children. During the last decade, mobile applications have been gaining importance and are slowly incorporated into everyday life. The inclusion of this kind of applications in the school area is mainly due to improvements in hardware and communication areas. As it was established, mobile learning is a young phenomenon that is being developed at great speed on behalf of the growing interest especially in the preschool educational area. During our research review we presented some of the most important existing mobile technologies that support children in kindergarten who face difficulties. Especially, mobile intervention tools that help children who face learning and math problems were investigated while applications that assess children with developmental, attention and mental problems were explored. Despite the fact that the area of the mobile learning is an area that needs more research we have the belief that this space for more study gives new hope for the special education. We have the belief that the sensitive age of preschool asks more investigation from the research groups in order to have more results in the educational areas that are explored. Additionally, the special education in kindergarten it is obvious that demands the support of the new technology and especially of the mobile learning which seems promising and appropriate for the needs of the special education. As a conclusion, we have to support the necessity of the design of more educational mobile applications for intervention and diagnosis of the learning difficulties in the kindergarten while we have to add the requirement of the training of the teachers and specialists in order to enhance the best results and effects in the development of the preschoolers who face such difficulties with the support of the mobile teaching.

\section{REFERENCES}

[1] Wartella, E. A., \& Jennings, N.:Children and computers: New technology. Old concerns. The future of children, 31-43 (2000) http://dx.doi.org/10.2307/1602688

[2] Bonsignore, E., Quinn, A. J., Druin, A., \& Bederson, B. B.:Sharing stories "in the wild": A mobile storytelling case study using StoryKit. ACM Transactions on Computer-Human Interaction (TOCHI), 20(3), 18(2013) http://dx.doi.org/10.1145/ 2491500.2491506

[3] Yahaya, N. S., \& Salam, S. N. A.: Mobile Learning Application for Children: Belajar Bersama Dino. Procedia-Social and Behavioral Sciences, 155, 398-404 (2014) http://dx.doi.org/10.1016/ j.sbspro.2014.10.312

[4] Muda, Z.: Storytelling Approach In Multimedia Courseware: An Introduction To Science For Preschool Education. In The 2nd International Conference on Information \& Communication Technologies (pp. 2991-2993)(2006)

[5] Kittidachanupap, N., Singthongchai, J., Naenudorn, E., Khopolklang, N., \& Niwattanakul, S. : Development of animation media for learning English vocabulary for children. In Computer Science and Automation Engineering (CSAE), 2012 IEEE International Conference on (Vol. 2, pp. 341-345). IEEE (2012, May) http://dx.doi.org/10.1109/csae.2012.6272788

[6] Farhana Md Ibharim, L., Borhan, N., \& Yatim, M. H.: A field study of understanding child's knowledge, skills and interaction towards capacitive touch technology (iPad). In Information Technology in Asia (CITA), 2013 8th International Conference on (pp. 1-5) IEEE (2013, July)

[7] Henderson, S., \& Yeow, J.: iPad in education: A case study of iPad adoption and use in a primary school. In System Science (HICSS), 2012 45th Hawaii International Conference on (pp. 7887) IEEE (2012, January)

[8] Melhuish, K., \& Falloon, G.: Looking to the future: M-learning with the iPad (2010). 
[9] Parsons, D., Ryu, H., \& Cranshaw, M.: A Design Requirements Framework for Mobile Learning Environments. Journal of Computers, 2(4), 1-8 (2007) http://dx.doi.org/10.4304/jcp.2.4.1-8

[10] Liebermana, D. A., Batesa, C. H., \& Soa, J.: Young Children's Learning With Digital Media. Computer in the Schools, 26(4), 271-283 (2009) http://dx.doi.org/10.1080/07380560903360194

[11] Kärnä-Lin, E., Pihlainen-Bednarik, K., Sutinen, E., \& Virnes, M.: Technology in Finnish Special Education-Toward Inclusion and Harmonized School Days. Informatics in education, 6(1), 103-114 (2007)

[12] Kärnä-Lin, E., Pihlainen-Bednarik, K., Sutinen, E., \& Virnes, M.: Technology in Finnish Special Education-Toward Inclusion and Harmonized School Days. Informatics in education, 6(1), 103-114, (2007)

[13] Biström, J.: Peer-to-peer networks as collaborative learning environments. In HUT T-110.551 seminar on internetworking (2005, April)

[14] Cavus, N., \& Uzunboylu: H. Improving critical thinking skills in mobile learning. Procedia-Social and Behavioral Sciences, 1(1), 434-438(2009) http://dx.doi.org/10.1016/j.sbspro.2009.01.078

[15] Prieto, J. C. S., Migueláñez, S. O., \& García-Peñalvo, F. J. : Understanding mobile learning: devices, pedagogical implications and research lines. Education in the Knowledge Society (EKS), 15(1), 20-42 (2014)

[16] Fernández-Cavia, J., \& López, M. : Communication, destination brands and mobile applications (2013)

[17] Hayes, G.R., Gardere, L.M., Abowd, G.D., and Truong, K.N. CareLog: A Selective Archiving Tool for Behavior Management in Schools. Proceedings of CHI 2008 p. 685-694, ACM, 2008 http://dx.doi.org/10.1145/1357054.1357164

[18] Monibi, M., \& Hayes, G. R. Mocotos: mobile communications tools for children with special needs. In Proceedings of the 7th international conference on Interaction design and children (pp. 121124). ACM (2008, June) http://dx.doi.org/10.1145/1463689. 1463736

[19] Bus, AG, Van IJzendoorn MH, Pellegrini AD: Joint book reading makes for success in learning to read. A meta-analysis on intergenerational transmission of literacy Rev Educ Res 65:1-21(1995)

[20] Segers E, \& Verhoeven L: Multimedia support of early literacy learning. Comput Educ 39:207-221(2002) http://dx.doi.org/10.1016/S0360-1315(02)00034-9

[21] Segers, E., Nooijen, M., \& de Moor, J.: Computer vocabulary training in kindergarten children with special needs. International Journal of Rehabilitation Research, 29(4), 343-345 (2006) http://dx.doi.org/10.1097/MRR.0b013e328010f4e0

[22] Virvou, M., \& Alepis, E.: Mobile educational features in authoring tools for personalised tutoring. Computers \& Education, 44(1), 53 68 (2005) http://dx.doi.org/10.1016/j.compedu.2003.12.020

[23] Jordan, N. C., Kaplan, D., Ramineni, C., \& Locuniak, M. N: Early math matters: kindergarten number competence and later mathematics outcomes. Developmental psychology, 45(3), 850864, (2009) http://dx.doi.org/10.1037/a0014939

[24] Duncan, G. J., Dowsett, C. J., Claessens, A., Magnuson, K., Huston, A. C., Klebanov, P., \& Japel, C.: School readiness and later achievement. Developmental psychology, 43(6), 1428 (2007) http://dx.doi.org/10.1037/0012-1649.43.6.1428

[25] Claessens, A., Duncan, G., \& Engel, M.: Kindergarten skills and fifth-grade achievement: Evidence from the ECLS-K. Economics of Education Review, 28(4), 415-427 (2009) http://dx.doi.org/10.1016/j.econedurev.2008.09.003

[26] Aunola, K., Leskinen, E., Lerkkanen, M. K., \& Nurmi, J. E.: Developmental dynamics of math performance from preschool to grade 2. Journal of Educational Psychology, 96(4), 699 (2004) http://dx.doi.org/10.1037/0022-0663.96.4.699

[27] Dowker, A.: Individual differences in numerical abilities in preschoolers. Developmental Science, 11(5), 650-654 (2008) http://dx.doi.org/10.1111/j.1467-7687.2008.00713.x

[28] Zaranis, N., Kalogiannakis, M., Papadakis, S: Using Mobile Devices for Teaching Realistic Mathematics in Kindergarten Education. Creative Education 4, p.1-10 2013 http://dx.doi.org/10.4236/ce.2013.47A1001

[29] Zaranis, N. : The influence of ICT on the numeracy achievement of Greek kindergarten children. In Moreira, M., Loureiro, J., Balu- la, A., Nogueira, F., Pombo, L., Pedro, L., \& Almeida, P. (Eds.) Proceedings of the 61 st International Council for Educational Media and the XIII International Symposium on Computers in Education (ICEM\&SIIE’2011) Joint Conference p.p.390-399, University of Aveiro, Portugal (2011)

[30] Chung, Y, \& Walsh, D. J: Constructing a Joint Story-Writing Space: The Dynamics of Young Children's Collaboration at Computers. Early Education and Development, 17, 373-420 (2006) http://dx.doi.org/10.1207/s15566935eed1703 4

[31] Räsänen, P., Salminen, J., Wilson, A. J., Aunio, P., \& Dehaene, S.: Computer-assisted intervention for children with low numeracy skills. Cognitive Development, 24(4), 450-472 (2009) http://dx.doi.org/10.1016/j.cogdev.2009.09.003

[32] Wei, C. W., Hung, I., Lee, L., \& Chen, N. S.: A Joyful Classroom Learning System with Robot Learning Companion for Children to Learn Mathematics Multiplication. Turkish Online Journal of Educational Technology-TOJET, 10(2), 11-23 (2011)

[33] French,D. P. :iPods: Informative or invasive?Journal of College Sc ienceTeaching, 36(1),p. 51-59 (2007)

[34] Tomi,A \&Rambli,D: An Interactive Mobile Augmented Reality Magical Playbook: Learning Number With The Thirsty Crow. Procedia Computer Science 25, p. 123-130, (2013) http://dx.doi.org/10.1016/j.procs.2013.11.015

[35] American Psychiatric Association. : DSM 5. American Psychiatric Association (2013)

[36] Re, A. M.,Mirandola, C., Esposito, S. S., \& Capodieci, A.: Spelling errors among children with ADHD symptoms: The role of working memory. Research in developmental disabilities, 35(9), p. 2199-2204 (2014) http://dx.doi.org/10.1016/j.ridd. 2014.05.010

[37] Blurton, C.: New Directions of ICT-Use in Education. Learning without frontiers. UNESCO World Communication and Information Report, 2007.

[38] Finnis, J. : Myths and facts of learning technology. TechLEARNING. Retrieved March 6, 2004, from http://www.techlearning.com/story/showArticle.jhtml? articleID=2 2101447 (2004)

[39] Gathercole, S. E., Alloway, T. P., Willis, C., \& Adams, A. M.: Working memory in children with reading disabilities. Journal of experimental child psychology, 93(3), p. 265-281, (2006) http://dx.doi.org/10.1016/j.jecp.2005.08.003

[40] Shipstead, Z., Hicks, K., \& Engle, R.: Cogmed working memory training: Does the evidence support the claims? Journal of Applied Research in Memory and Cognition 1,p. 185-193, (2012) http://dx.doi.org/10.1016/j.jarmac.2012.06.003

[41] Kharazmi, R. Najafi, M., Khoshnavay,F. : Mobile phone an effective tool for management process of ADHD. International Journal of Managment, IT and Engineering, 3, p. 141-151, (2013)

[42] Kagohara,D., van der Meer,L., Ramdos,S.,O’Reilly ,M., Lancioni,G., Davis,T., Rispoli ,M.,Lang,R., Marschik,P., Sutherland,D., Green,V., Sigafoos. J.: Using iPods1 and iPads1 in teaching programs for individuals with developmental disabilities: A systematic review. Research in Developmental Disabilities 34, p. 147-156 (2013) http://dx.doi.org/10.1016/j.ridd.2012.07.027

[43] Waddington, E. M., \& Reed, P.: The impact of using the "Preschool Inventory of Repertoires for Kindergarten"(PIRK®) on school outcomes of children with Autistic Spectrum Disorders. Research in Autism Spectrum Disorders, 3(3), p. 809-827(2009) http://dx.doi.org/10.1016/j.rasd.2009.03.002

[44] Venkatesh, S., Greenhill, S., Phung, D., Adams, B., \& Duong, T.: Pervasive multimedia for autism intervention. Pervasive and Mobile Computing, 8(6), p. 863-882 (2012) http://dx.doi.org/10.1016/j.pmcj.2012.06.010

[45] Peca, A., Simut, R., Pintea, S., Costescu, C., \& Vanderborght, B.: How do typically developing children and children with autism perceive different social robots? Computers in Human Behavior, 41, p. 268-277 (2014) http://dx.doi.org/10.1016/j.chb.2014.09.035

[46] Kamerow, D.: 2Regulating medical apps: which ones and how much?. BMJ, 347 (2013)

[47] Choe, E. K., Lee, N. B., Lee, B., Pratt, W., \& Kientz, J. A.: Understanding quantified-selfers' practices in collecting and exploring personal data. In Proceedings of the 32 nd annual ACM confer- 
ence on Human factors in computing systems (pp. 1143-1152). ACM (2014, April) http://dx.doi.org/10.1145/2556288.2557372

[48] [48] Dennis, T. A., \& O'Toole, L. J.: Mental health on the go effects of a gamified attention-bias modification mobile application in trait-anxious adults. Clinical Psychological Science, 2167702614522228 (2014)

[49] Malchiodi, C. A. (Ed.).: Handbook of art therapy. Guilford Press (2011)

[50] Falloon, G.: Young students using iPads: App design and content influences on their learning pathways. Computers \& Education, 68, 505-521 (2013) http://dx.doi.org/10.1016/j.compedu.2013. 06.006

[51] Malchiodi, C. A. (Ed.).: Art therapy and health care. Guilford Press (2012)

[52] Leuty, V., Boger, J., Young, L., Hoey, J., \& Mihailidis, A.: Engaging older adults with dementia in creative occupations using artificially intelligent assistive technology. Assistive Technology, 25(2), 72-79 (2013) http://dx.doi.org/10.1080/10400435.2012. 715113

[53] Sendlinger, S. C., DeCoste, D. J., Dunning, T. H., Dummitt, D. A., Jakobsson, E., Mattson, D. R., \& Wiziecki, E. N.: Transforming chemistry education through computational science. Computing in Science \& Engineering, 10(5), 34-39 (2008) http://dx.doi.org/10.1109/MCSE.2008.124

[54] Potter, L. E., Korte, J., \& Nielsen, S.: Sign my world: lessons learned from prototyping sessions with young deaf children. In Proceedings of the 24th Australian Computer-Human Interaction
Conference, p.501-504, ACM (2012, November) http://dx.doi.org/10.1145/2414536.2414613

\section{AUTHORS}

Athanasios Drigas is a Research Director at IITN.C.S.R. Demokritos. He is the Coordinator of Telecoms $\mathrm{Lab}$ and founder of Net Media Lab since 1996. From 1985 to 1999 he was the Operational manager of the Greek Academic network. He has been the Coordinator of Several International Projects, in the fields of ICTs, and eservices (e-learning, e-psychology, e-government, einclusion, e-culture etc). He has published more than 270 articles, 7 books, 25 educational CD-ROMs and several patents. He has been a member of several International committees for the design and coordination of Network and ICT activities and of international conferences and journals. (e-mail: dr@iit.demokritos.gr).

Georgia Kokkalia (MSc in Specific Learning Difficulties) is a Special Education Teaching Professional. She has participated in various research projects regarding the use of Information and Communication Technologies (ICTs) in Special Education and in Kindergarten. (e-mail: gioulina@hotmail.com).

Submitted 17 November 2015. Published as resubmitted by the authors 27 December 2015. 